\title{
Mais Categorias Diagnósticas? Interlocuções Entre Saúde Mental e Educação
}

\section{More Diagnostic Categories in DSM? Interlocutions between Mental Health and Education}

\author{
Ana Flávia Pedrosa Lopes*a; Cristiana Carneiro ${ }^{a}$
}

aUniversidade Federal do Rio de Janeiro. RJ, Brasil.

*E-mail: anaflaviaplopes@outlook.com.

\begin{abstract}
Resumo
O presente artigo problematiza a proliferação dos transtornos conduzida pelo Manual Diagnóstico e Estatístico dos Transtornos Mentais. Introduz uma discussão sobre diagnóstico e medicalização, indicando um movimento crescente de compreensão dos problemas da vida como doença. Apresenta um levantamento sobre o aumento do quantitativo de categorias diagnósticas das edições do Manual Diagnóstico e Estatístico dos Transtornos Mentais, refletindo sobre seus possíveis impactos na educação. Por fim, apresenta alguns aspectos do cenário educativo atual, que podem estar se constituindo em reflexos dessa ampliação.
\end{abstract}

Palavras chave: DSM. Educação. Medicalização. Psicanálise.

\begin{abstract}
This article discusses the disorders proliferation conducted by the Diagnostic and Statistical Manual of Mental Disorders (DSM). It introduces a discussion on diagnosis and medicalization, pointing a growing movement of understanding life's problems as a disease. It presents a survey on the increase in the amount of diagnostic categories of the Diagnostic and Statistical Manual of Mental Disorders (DSM) editions, reflecting on their possible impacts on education. Finally, it presents some aspects of the current educational scenario that may indicate an increase in the use of this manual, especially from its most recent editions.
\end{abstract}

Keywords: DSM. Education. Medicalization. Psychoanalysis.

\section{Introdução}

A partir da perspectiva teórica da psicanálise e por meio da metodologia qualitativa de levantamento bibliográfico, o presente artigo tem como objetivo principal conduzir uma reflexão sobre a proliferação dos transtornos, ao longo dos anos, e sobre as possíveis consequências dessa proliferação na educação. Para seu desenvolvimento, os materiais centrais utilizados foram os Manuais Diagnósticos e Estatísticos de Transtornos Mentais em todas as suas versões. Dialogando com este material, autores mais antigos como Foucault (1968, 1972) e Illich (1982), referências essas utilizadas para uma discussão acerca de como a Medicina começou a ocupar o espaço através de normas e condutas. Também foi utilizada uma bibliografia mais recente, com autores como: Birman (2014), Canguilhem (2014), Dunker (2014), que se voltam para a discussão acerca da medicalização e das consequências da multiplicação dos transtornos mentais, até chegar a autores como Coutinho e Carneiro (2016), Patto (2000) e França (2012) e Lima (2019), que se voltam, principalmente, sobre o mal-estar escolar.

\section{Desenvolvimento}

\subsection{Metodologia}

Ao se procurar o sentido atual da palavra diagnóstico, se vê que se relaciona ao exame médico e sua busca para encontrar a razão e a natureza da afecção, a determinação de uma doença a partir da descrição de seus sintomas (AURÉLIO, 2019). No entanto, se voltar a sua origem, a etimologia da palavra diagnóstico, se vê que vem "do grego Diayvon, discernimento, decisão. É o processo que se utiliza para chegar a uma conclusão. É também o nome dado à conclusão em si mesma (SIMÕES et al., 2014). É sobre estas duas possibilidades diferenciadas que se decidiu dar início à presente reflexão. Se, etimologicamente, se pode pensar o diagnóstico mais pelo viés do processo, ou mais pelo viés da conclusão, pode-se também perguntar se na atualidade a política que segue padrões normativos para a nova produção de categorias diagnósticas estaria minimizando o processo em prol da conclusão, ou ainda, a produção de categorias, que definem o sofrimento mental dos sujeitos pautado em uma perspectiva com base neurobiológica, atrelada a uma nomenclatura com uma linguagem comum, dirigida ao campo descritivo e operacional, não estaria reduzindo o processo?

A importância da investigação sobre a proliferação dos transtornos conduzida pelo Manual Diagnóstico e Estatístico dos Transtornos Mentais tem caráter político e epistêmico, por conta de o manual estar associado ao Código Internacional de Doenças (CID), sendo esse código uma das diretrizes diagnósticas utilizadas pelo Sistema Único de Saúde (SUS). 
Além disto, o DSM, estando associado ao Código Internacional de Doenças (CID) se "tornaram de tal forma hegemônicos, que ofuscaram a existência de possibilidades distintas de nomear e organizar as psicopatologias, incluindo aquelas da faixa etária infantil e juvenil” (LIMA, 2019, p.173).

Para Dunker (2014, p. 102), o termo "transtorno" já exprime uma tentativa de diagnóstico "a-teórico", ou seja, distanciado das grandes teorias explicativas, em que a causalidade de uma patologia deixa de ser o alicerce central do processo diagnóstico. A proposição a-teórica pretende se ocupar de uma solução dita imparcial, na qual qualquer orientação pudesse se utilizar de tais nomenclaturas. Esses manuais diagnósticos construíram uma proposição, na qual a identificação de um transtorno mental ocorre pautada somente nos fenômenos observáveis.

A CID-10 sustenta alguns pressupostos em comum com o DSM-IV-TR como a ênfase de que é ateórico - o que não significa que não haja um saber no comando. Isso significa apenas que para eles uma teoria é sempre partidária e a proposição que fazem é de que o saber não pode ser partidário. Disso, decorre a opção pelo descritivismo como um saber sem sujeito a partir de definições claras dos termos a serem utilizados (RESENDE; CALAZANS, 2013, p.148).

Como bem mostrou Foucault (1981), no marco do surgimento da ciência moderna, a Medicina se constituiu como um discurso de controle social, portanto jamais neutra. Foucault se interessou em responder à pergunta sobre como um dispositivo de poder pode produzir certo número de enunciados e discursos, em consequência das formas de representação que podem surgir dali? Para o autor, tais dispositivos de poder incidem na produção das práticas discursivas. Com a biopolítica, o que se constata é uma relação entre o controle da vida e o modelo biológico, transformando a vida em objeto de saber (FOUCAULT, 1981). Com isso, o discurso da Medicina ocupa, preponderantemente, o espaço, enunciando sempre seu saber, isto é, uma vigilância contínua do espaço social, seja físico ou temporal, através de normas e condutas ditas adequadas.

Illich (1982) também traz a noção de medicalização em seus trabalhos, alertando que a expansão do poder médico diminuía a forma como as pessoas lidavam com suas dores e sofrimentos, pois estes eram transformados em doenças. O autor isola três formas de iatrogênese social: 1 . a medicalização do orçamento; 2. a invasão farmacêutica; 3 . a medicalização das categorias sociais. A primeira forma leva determinado público a crer que a saúde aumenta, proporcionalmente, em relação aos medicamentos, internações e terapêuticas. A segunda forma de iatrogênese social seria a invasão farmacêutica, constatada a partir do aumento drástico de prescrições medicamentosas. Esse aumento revela como os médicos passam a orientar sua ação não pela busca etiológica, mas pelos sintomas, de forma que fica evidente a tomada do saber médico por um pseudosaber farmacêutico (ILLICH, 1982).

A terceira forma de iatrogênese, colocada por Illich (1982), é a medicalização das categorias sociais. Redunda na crença da necessidade de certos cuidados médicos de praxe pelo fato de se enquadrarem em determinada fase da vida, como por exemplo, serem recém-nascidas, serem crianças, estarem no climatério ou na velhice. Nessa ótica, se constrói uma forte aliança entre o discurso médico e a produção da infância, envolvendo também a escola, já que desenha uma espécie de perfil de aluno que se inter-relaciona fortemente com o que se espera dele nas diferentes idades.

Indo nesta direção, assistiu-se, nas duas últimas décadas do século XX, a um incremento significativo de encaminhamentos da escola à saúde mental, o que vem crescendo ainda mais nesta segunda década do século XXI, no Brasil (BOARINI; BORGES,1998; COLLARES, 2013; CARNEIRO; COUTINHO, 2015). Está se assistindo a um aumento alarmante de patologias na infância e adolescência, ou se estaria interpretando uma nova forma de ser no contemporâneo (diante da qual ainda pouco se sabe) como doença? O Brasil é o segundo maior consumidor mundial do psicofármaco metilfenidato, a chamada droga da atenção, e a infância e adolescência são seu principal público (Portal UNICAMP). Moysés (2013), Viegas, Harayama e Souza (2015) e Caliman (2009) vêm sistematicamente chamando a atenção para o aumento alarmante da medicalização na educação, ou seja, o aumento exponencial da compreensão daquilo que não vai bem na escola como resultado de patologias individuais da infância e adolescência, uma leitura que vai no sentido contrário de as pensar como socialmente produzidas. A medicalização como destino dado aos alunos "desadaptados", muitas vezes, acaba cronificando e patologizando um percurso. A lógica medicalizante, na escola, acredita ser possível consertar, corrigir - muitas vezes através do medicamento - o suposto desvio. O problema aqui não são os cuidados, certamente, é a ilusão de erradicação do "erro", como se fosse possível viver em um mundo pleno, no qual a felicidade também pudesse ser atingida de forma cabal e definitiva. A "produção do fracasso escolar" (PATTO, 2000) individualizaria o fracasso, fazendo a responsabilidade recair sobre o aluno e seu "déficit", excluindo a própria escola e cena escolar da produção do mal-estar.

Como se pode ver, as consequências da medicalização e biologização da vida se inserem no viver de formas diversas e complexas. Neste cenário de grandes modificações, em que o discurso médico se espraia por diversos espaços, interessa perguntar como se chega à atual proliferação dos transtornos e quais possíveis reflexos se poderia estar assistindo na educação.

\subsection{A proliferação dos transtornos}

O modelo bioquímico ascende, a partir de 1950, substituindo o modelo biológico pautado na hereditariedade. A partir dessa ascensão, as referências atuais em diagnóstico que dominam o campo da psiquiatria são o Código Internacional 
de Doenças (CID) e o Manual Diagnóstico e Estatístico dos Transtornos Mentais (DSM). Desses decorrem alguns impasses referentes à temática do diagnóstico:

1. a ocorrência de múltiplos diagnósticos psiquiátricos para um mesmo sujeito em sofrimento psíquico. Impasse relativo à comorbidade e a ocorrência, em um mesmo sujeito em sofrimento psíquico, de hipóteses diagnósticas distintas.

2. a prescrição de psicofármacos obedece a essa proporcionalidade, sugerindo polimedicação, já que se observa o uso de vários fármacos e psicofármacos no mesmo sujeito em sofrimento psíquico - incluindo fármacos $\mathrm{e}$ psicofármacos não sujeitos à receita médica, de medicinas alternativas e suplementos dietéticos.

A tendência ao múltiplo diagnóstico e a polimedicação são tributários de uma busca por soluções mais imediatas para o sofrimento psíquico. Esses processos descritos acima acabam facilitando cada vez mais a adesão à indústria farmacêutica. Como já referido, o diagnóstico dentro da Medicina, especialmente na esfera da psiquiatria, se pauta predominantemente na observação. O método da observação contribuiu para constituição de um campo psiquiátrico constituído de síndromes e classificações determinadas, de modo que, mesmo sem o artifício da localização de lesões, uma nosografia seja delineada. A fala, neste modelo, não é tida como um instrumento central no diagnóstico, muito menos de cura. Buscando a objetividade científica, a observação se orienta a partir de agrupamentos de categorias psicopatológicas, de forma que meramente com o olhar, o discernimento entre equivalente e díspar poderia ser feito.

De acordo com Costa (1950) se encontram modelos diagnósticos pautados na observação direta, definindo o objeto como um fato publicamente observável, o que minimizaria a centralidade do fator etiológico. Sobretudo, em relação ao DSM, com sua perspectiva pautada na neurobiologia, a classificação se faz a partir de critérios de duração e de repetição.

O transtorno, nome que aparece ao longo dos Manuais diagnósticos, é considerado um déficit de uma substância neuronal e a medicação entra em cena de modo compensatório (DUNKER, 2014).

No Manual, como o termo transtorno não é, e não pode ser utilizado como forma de determinar a causa, de forma a somente agrupar os sintomas sem a preocupação etiológica, a sua essência classificatória é evidente. De acordo com o próprio Manual, esse se propõe a "a servir como um guia prático, funcional e flexível para organizar informações que podem auxiliar o diagnóstico preciso e o tratamento de transtornos mentais" (APA, 2013). Isso chama a atenção, pois logo no prefácio do manual já fica claro qual é o objetivo do mesmo, ser prático e flexível. Seria uma pressa no diagnóstico? Uma simplificação diagnóstica?

Prosseguindo na leitura do Manual, em sua introdução, com a determinação dos ditos transtornos, observa-se como essa palavra foi escolhida para a classificação dos sinais e dos sintomas observáveis, o que resulta em uma problemática em relação ao seu agrupamento. Observa-se como há uma dificuldade na classificação categórica dos transtornos, pois:

reconhecemos que transtornos mentais nem sempre se encaixam totalmente dentro dos limites de um único transtorno. Alguns domínios de sintomas, como depressão e ansiedade, envolvem múltiplas categorias diagnosticas e podem refletir vulnerabilidades subjacentes comuns a um grupo maior de transtornos. (APA, 2013).

Observa-se que até os anos de 1980, o DSM era pautado pelo modelo psicodinâmico, mas posteriormente o foco se voltou aos estudos cognitivos articulados a um paradigma estatístico e psicométrico. O Manual Diagnóstico e Estatístico das Doenças Mentais foi criado a partir de uma concordância sobre a reunião de sintomas, que especificam um transtorno que reúne sinais e sintomas com determinada duração, não levando em conta a estrutura psíquica, bem como a resposta ou o modo de defesa. Nessa direção:

os limites entre várias 'categorias' de transtornos são mais fluidos ao longo do curso de vida do que os identificados pelo DSM-IV, e vários sintomas atribuídos a um único Transtorno podem ocorrer, em diferentes níveis de gravidade, em vários outros transtornos (APA, 2013, p.5).

Retomando um breve histórico das edições do DSM, é possível depreender a forma como se organizou a temática do diagnóstico em psiquiatria no espaço de sessenta e seis anos. A primeira edição do DSM data do ano de 1952 e a quinta edição, do ano de 2013. O Quadro 1 sintetiza as edições sucessivas do DSM (DSM I; DSM-II; DSM-III; DSM-III-TR; DSM-IV; DSM-IV-TR e DSM-5):

Quadro 1 - Síntese das edições do DSM

\begin{tabular}{|c|c|c|c|c|}
\hline Edições do DSM & Ano de Publicação & Número de Páginas & $\begin{array}{c}\text { Categorias } \\
\text { Diagnósticas }\end{array}$ & $\begin{array}{c}\text { Fundamentação } \\
\text { Epistemológica }\end{array}$ \\
\hline DSM -I & 1952 & 132 & 106 & Modelo psicanalítico \\
\hline DSM -II & 1968 & 134 & 182 & Modelo psicanalítico \\
\hline $\begin{array}{c}\text { DSM -III/ } \\
\text { DSM -IITR }\end{array}$ & $1980 / 1987$ & $494 / 597$ & $265 / 292$ & $\begin{array}{c}\text { Modelo Médico/ } \\
\text { biológico }\end{array}$ \\
\hline $\begin{array}{c}\text { DSM -IV/ } \\
\text { DSM -IVTR }\end{array}$ & $1994 / 2000$ & 886 & 374 & $\begin{array}{c}\text { Modelo Médico/ } \\
\text { biológico }\end{array}$ \\
\hline DSM -5 & 2013 & 992 & 300 & $\begin{array}{c}\text { Modelo Médico/ } \\
\text { biológico }\end{array}$ \\
\hline
\end{tabular}

Fonte: dados da pesquisa. 
Anteriormente ao DSM-III, a classificação dos DSM-I e o II ainda comportava a distinção diagnóstica entre a neurose e a psicose. O DSM-III foi um marco na história da psiquiatria moderna, pois foi a partir desse, na década de 1980, que apareceu a elaboração de uma taxonomia pluralizada de psicopatologias pautadas no modelo neurobiológico.

Com a elaboração do DSM-5 (2013), já na introdução desta edição se encontra a afirmação de que o DSM corresponde à necessidade de aprofundamento e expansão da classificação em psiquiatria para garantir maior precisão descritiva do transtorno e validade do diagnóstico. O diagnóstico em torno dos sinais e sintomas dispensa a dimensão teórica que fundamenta a pesquisa dos fatores subjetivos, que condicionam a formação do sintoma. Como diz Birman (2014), articulado a um protocolo de decisões terapêuticas, que têm como base o desenvolvimento das neurociências e a tecnologia dos psicofármacos, o diagnóstico exclui a necessidade de escuta do conteúdo discursivo do paciente em sua dimensão específica de sujeito para avaliação dos processos psíquicos causais do desencadeamento das diversas versões do sofrimento psíquico e do manejo clínico para a estabilização.

De acordo com o Manifesto de São João del-Rei (CALAZANS et al, 2012), escrito no Brasil, a consequência do DSM é a criação de verdadeiras "epidemias psíquicas" voltadas para a infância e a adolescência: os chamados transtornos de déficit de atenção e hiperatividade (TDAH) e os casos de autismo (TEA).

Nesse Manifesto se constata que o aumento de casos de TDAH diagnosticados nos Estados Unidos foi de $500 \mathrm{mil}$ casos em 1997 para cerca de 4 milhões e 400 mil casos em 2012. Em relação ao autismo houve um aumento em mais de $2.700 \%$ nos diagnósticos. Esse aumento epidêmico está relacionado diretamente com o uso dos DSMs, ressaltando que muitas vezes o diagnóstico pode ter sido feito de forma errônea, já que apenas a presença dos sintomas não define uma patologia específica (CALAZANS et al., 2012).

Juntamente com as mudanças diagnósticas, Allen Frances, que participou da elaboração do DSM-IV, pontua o aumento alarmante dos diagnósticos de TDAH de forma não criteriosa pelos médicos, bem como as consequências que os médicos educados pela indústria farmacêutica podem acarretar. Frances também alertou já, em 2010, que com a chegada do DSM 5 a ocorrência do TDAH aumentaria, pois o número de itens para a ocorrência dos sintomas da tabela iria diminuir de seis para três.

No Brasil, o número de medicamentos vendidos é alarmante, em relação ao TDAH entre os anos de 2000 e 2004 o aumento nas vendas de metilfenidato foi de $1.020 \%$, e entre 2004 e 2008 o aumento foi de $930 \%$, sendo que o aumento das vendas significa o aumento dos casos (CALAZANS et al., 2012).

\subsection{Análise}

Observa-se que existe uma diferença na maneira de fazer o diagnóstico na psiquiatria contemporânea. Uma primeira diferença, já referida ao longo deste texto, foi a distinção de fundo teórico, que se relaciona com o divórcio da forma de fazer o diagnóstico. O DSM é um manual que não fala da teoria, mas somente da sintomatologia, é um manual de reconhecimento. Portanto, essa ausência de proposições teóricas também converge para a questão da fragmentação do diagnóstico. Para Resende e Calazans (2013), uma hipótese importante é a de que o a-teorismo do Manual é usado de forma estratégica, de forma a esconder a não confirmação de um marcador biológico. Para os autores há uma espécie de contradição «escondida» nos recentes manuais. Ao mesmo tempo em que o a-teorismo apaga as grandes questões etiológicas da psicopatologia clássica, a indicação de causas neurobiológicas parece descrever uma etiologia orgânica, ainda que não comprovada. Dessa forma, reedita-se a questão de uma concepção organicista ou não do sofrimento psíquico. Se o marcador biológico não é encontrado, como chegar à afirmação etiológica? A consequência que se pode extrair é que a afirmação etiológica, nesse caso, é mais discursiva do que propriamente uma descoberta epistêmica.

Uma segunda diferença é a mudança na ferramenta de escuta, justamente do conteúdo discursivo, pois essa escuta é pautada na orientação do reconhecimento dos sintomas, sendo uma escuta completamente diferente da baseada na teoria psicanalítica. De acordo com Dunker (2014), ao excluir as relações entre os sintomas e o funcionamento psíquico dos sujeitos, o enfoque é voltado para o relato apenas do sintoma. A vida pessoal é vista em setores, em partes de uma grande loja de departamentos, que transformou a administração do mal-estar em sintomas, sem a mediação da categoria central de sofrimento. Portanto, sem a noção de sofrimento, a experiência de reconhecimento vista como um elemento transformador do sintoma é excluída. Nessa lógica, o sofrimento parece correspondente à dor, logo, uma mera secreção orgânica dos neurônios.

Dessa forma, com o DSM, o reconhecimento do malestar que preside a insuficiência das articulações entre sofrer e ter um sintoma, não é feito. A expansão dessa forma de sofrimento, dada pelo manual, tem consolidado a exportação de determinadas palavras chaves na fala dos pacientes, para que os mesmos possam ser incluídos em dispositivos de tratamento e saúde subvencionados pelo Estado e, também, por companhias de seguro (DUNKER, 2014).

Se, como demonstrado, houve uma proliferação de categorias pela psiquiatria, para além de suas consequências dentro da própria área médica e da saúde mental, se poderia pensar em possíveis influências em âmbito mais expandido?

Com o abandono do modelo psicodinâmico, o debate etiológico em relação ao sofrimento psíquico, dentro da psicopatologia atual, fica muito diminuído e, portanto, pouco 
aderente à hipótese da causalidade psíquica. Se todos esses fatores impactam diretamente as formas de diagnóstico na saúde mental, como pensar essa relação com a educação? Por que haveria sentido em se debater o DSM, manual específico da saúde mental, no campo educativo? Justamente porque esses dois campos disciplinares - saúde mental e educação - embora muito distintos exercem grandes influências recíprocas. Se por um lado a escola é uma das grandes instituições de encaminhamento de crianças e adolescentes para os atendimentos de saúde mental, a saúde mental, na atualidade, parece emprestar aos educadores nomes de transtornos que explicariam certos comportamentos das crianças e adolescentes. Nesse sentido, se pode hipotetizar que a proliferação de transtornos no DSM e a modalidade atual de se diagnosticar em saúde mental, mais voltada aos sintomas, pode estar facilitando certo "transbordamento" desses nomes para o interior da escola.

Outro provável fator que aumentou as nomeações inspiradas no DSM dentro da escola foi a disseminação das informações em rede. No entanto, é importante ressaltar que o campo da saúde mental não é homogêneo, e o que se veio descrevendo aparece mais como tendência do que unanimidade. Chegou ao Brasil, em 2018, por exemplo, a tradução da Classificação Francesa dos Transtornos Mentais da Criança e do Adolescente, cuja proposta não advoga o a-teoricismo, utilizando substancialmente a psicanálise como proposta teórica (LIMA, 2019). Todavia, seja pela diferença temporal em termos de publicação no Brasil, seja por certa filiação ao modelo americano estadunidense e sua sugerida praticidade, esse modelo francês não ocupa, na saúde mental, um lugar de protagonismo, quando se pensa em diagnóstico.

\subsection{Possíveis resultados da proliferação de categorias diagnósticas na educação}

Bezerra Junior (2014) indica que toda classificação supõe um autor, um agente, um princípio classificador e um eixo ordenador que preside a criação das categorias, que compõem e organizam, de forma hierárquica, a sua distribuição. Dessa forma, para o autor, toda a classificação tem uma destinação, visando um objetivo, tem um contexto de criação e uma história. As classificações psiquiátricas, portanto, têm todos esses elementos, mas por serem utilizadas em contextos relacionais e incidirem sobre os indivíduos, que vivem em ambientes sociais complexos, acabam alcançando uma importância social decisiva por refletirem no interior de sua lógica aspectos constitutivos da cultura e se tornarem, pela força performativa de suas categorias, verdadeiros atores sociais, com forte poder de agenciamento na vida subjetiva dos indivíduos. Dessa forma, observa-se como os quadros diagnósticos psiquiátricos se tornaram culturalmente disseminados, presentes não somente na prática psiquiátrica strictu sensu, mas também dentro do campo da educação, na assistência à saúde e na linguagem cotidiana.

Pensando no contexto ampliado da educação, no processo de escolarização no Brasil, se verá que seu público-alvo é composto, predominantemente, por crianças e adolescentes. Estes passam boa parte dos seus dias e de suas vidas no ambiente escolar. Nesse sentido, para além da família, a escola é o principal ambiente formador de crianças e adolescentes. Nesse sentido, pensar como a proliferação das categorias diagnósticas pode estar chegando à educação, é também pensar em seus agenciamentos na vida subjetiva de crianças e jovens.

No trabalho de Carneiro e Coutinho (2015), baseado na análise documental de prontuários sobre queixas ligadas à escolarização, dentro do serviço universitário de psiquiatria, pode ser lido que bom número de crianças chegam indicadas pela escola. É importante salientar que dentro desse trabalho, nos 285 casos analisados, 92 foram referentes à escola, sendo que em 43 destes casos a escola apareceu como a própria identificadora dos problemas, ou seja, a escola se encontra em uma posição muito expressiva em identificar e encaminhar as crianças e adolescentes para o setor de psiquiatria da infância e adolescência.

Se, por um lado, como já apontava Mannoni (1999), a escola abre, muitas vezes, uma segunda chance para a criança, ofertando um espaço outro, diferente da família, no qual ela pode encontrar um novo lugar, por outro lado, a oferta de nomeações patologizantes no seio da escola, como já dito, não é neutra. Muitas vezes, os nomes dos transtornos circulam na escola com certa facilidade, quase como sinônimos de certas características. Nesta espécie de pseudodiagnóstico escolar não há delongas temporais, rapidamente características são resumidas em transtornos. Se pode falar de uma informalidade diagnóstica nesses casos, há ainda certos diagnósticos que se valem, oficialmente, do papel do professor, como o uso de escalas avaliativas. Portanto, constata-se uma mudança na forma de se pensar o diagnóstico, que perpassa inclusive a área da educação.

$\mathrm{Na}$ medida em que o diagnóstico passa a ser concebido, predominantemente, pelo neurobiológico e comportamental, os sujeitos da cena desaparecem, sua fala e narrativa ficam secundarizadas em prol da identificação de uma soma de características biológicas e comportamentais, ou seja, a escola nesse caso ocupa um lugar muito relevante, sendo aquela que tem o papel de identificar comportamentos e características e encaminhar a criança/adolescente para a saúde mental (CARNEIRO; COUTINHO, 2015). Um bom exemplo da expansão diagnóstica para o interior da escola é o uso de uma escala de pontuação para pais e professores (MTA-SNAPIV). Através da utilização do questionário SNAP-IV ${ }^{1}$, por

1 O questionário denominado SNAP-IV foi construído a partir dos sintomas do Manual de Diagnóstico e Estatístico - IV Edição (DSM-IV) da Associação Americana de Psiquiátrica. É um questionário utilizado como um ponto de partida para levantamento de alguns possíveis sintomas primários do TDAH. 
profissionais da área de educação, busca-se identificar as principais características e sintomas do Transtorno do Déficit de Atenção e Hiperatividade em crianças e adolescentes.

Como indica o trabalho de Marcon, Sardagna e Schussler (2016), o objetivo é oferecer uma ferramenta diagnóstica que permita aos profissionais da educação realizarem um prédiagnóstico da possível presença desse transtorno em crianças ou jovens inseridos no contexto escolar. O uso do questionário aparece, então, como ferramenta coadjuvante no diagnóstico do TDAH, especialmente, por parte dos educadores. Neste instrumento se poderia estar vendo, de forma aplicada, ressonâncias da "praticidade, funcionalidade e flexibilidade" do DSM -IV? Lembre-se que o mesmo se propõe "a servir como um guia prático, funcional e flexível para organizar informações que podem auxiliar o diagnóstico preciso e o tratamento de transtornos mentais" (APA, 2013).

Acreditando que as "categorias diagnósticas não apenas descrevem os sintomas dos pacientes, esses os moldam, ao criarem roteiros de identificação e designação das experiências de sofrimento, além de indicar modos de responder, técnica e socialmente, a elas" (BEZERRA JUNIOR., 2014, p.12), concordando que além de uma dimensão descritiva, estas categorias mostram uma poderosa força prescritiva.

Outro ponto importante para se refletir sobre a proliferação de categorias diagnósticas, em sua articulação com a educação, é sua relação com as não aprendizagens. Coutinho Carneiro e Carneiro (2016), em outro artigo, denominado "Infância, adolescência e mal-estar na escolarização: interlocuções entre a psicanálise e a educação", constatam como a medicalização produz um novo modo de lidar com o fracasso escolar. Verificase como as crianças, de acordo com essa perspectiva, passam a sofrer de "patologias", que justificam a não aprendizagem e a inadequação à escola, na qual os transtornos se proliferam concomitantemente à oferta variada de substâncias químicas para curá-los.

Pode-se pensar no possível impacto da proliferação diagnóstica sobre a aprendizagem, por exemplo, quanto ao uso das salas de recurso nas escolas públicas. A sala de recursos, geralmente, é utilizada por aqueles alunos que estão apresentando alguma dificuldade com a aprendizagem. Nessa se espera um atendimento mais particularizado das crianças e adolescentes. $\mathrm{O}$ uso da sala de recursos não se dirige, portanto, a todos os alunos e alunas. De caráter eletivo e voltada à aprendizagem, cabe a cada escola indicar e selecionar quais crianças e/ou adolescentes seriam sua clientela. Como as instituições estão fazendo suas escolhas?

De forma bastante curiosa, visto se tratar de um espaço específico de ensino e aprendizagem, cuja regulação não especifica a participação médica, apesar da práxis apontar outra coisa. Pode-se notar, por exemplo, que apesar da Nota Técnica 04/2014 do MEC/SECADI/DPEE, que fez cair a exigência de um laudo médico para incluir uma criança com dificuldades na escola, na prática, sobretudo, quanto à utilização das salas de recursos nas escolas municipais do Rio de Janeiro, espera-se e solicita-se o laudo médico. Circula em muitas escolas o termo "criança laudada", o que revela a contradição entre leis, normativas e direitos e sua implantação na prática. Aqui se pode aventar que a doença ratificada por um profissional médico justificaria mais o uso da sala do que o olhar do professor, especialista em ensino e aprendizagem. Estaria o médico mais apto que o educador a saber quais crianças se beneficiariam deste espaço específico de aprendizagem?

Ampliando o uso da escala e do laudo, outra iniciativa envolvendo a escola e os novos transtornos foi a criação da lei municipal do Rio de Janeiro, número 5416 de 29/05/2012, que dispõe sobre as diretrizes adotadas pelo município para realizar a orientação a pais e professores da cidade do Rio de Janeiro sobre as características do transtorno do déficit de atenção - TDA. Não à toa, a indústria farmacêutica Novartis produziu e distribuiu, gratuitamente, um material educativo sobre TDAH dirigido a pais e educadores. Segundo o Fórum sobre Medicalização da Educação e da Sociedade (http:// medicalizacao.org.br/, recuperado em 12 de setembro, 2019), em alguns Estados, projetos deste tipo encontraram resistência como foi o caso de São Paulo, que construiu um manifesto de repúdio ao Projeto de Lei $n^{\circ}$ 0086/2006 sobre o programa de apoio ao aluno com dislexia. Mais uma vez aqui se aponta que o movimento de resistência se faz no sentido contrário a uma institucionalização da doença, em que pais e educadores iriam 'aprendendo ' cada vez mais sobre o suposto transtorno e com isto sedimentando sua naturalização.

Para além desses efeitos mais objetivos supracitados, concretizados em instrumentos e leis, se têm os impactos da nomeação dos transtornos na relação com o outro, que se passam no próprio cotidiano da escola. Seja entre professores e alunos, seja entre a escola e a família, seja entre os pares aluno/aluno, parece estar havendo um transbordamento do diagnóstico da saúde mental para o dia a dia da escola. Hipotetiza-se com isso que o modo "prático e rápido" de se diagnosticar, pautado na identificação dos sintomas, está de mãos dadas com a medicalização da vida e da educação. Crianças e adolescentes, não poucas vezes, acabam por explicar seu insucesso na escola a partir de um diagnóstico, ou pseudodiagnóstico, recebido por algum especialista ou educador, ou até por uma autonomeação incrementada pelas buscas na internet, sobretudo, em adolescentes. Nesses casos, o diagnóstico é usado pelos próprios sujeitos como ancoragem identitária. Para Bezerra Junior (2014, p. 12): “o encontro com o diagnóstico modifica sensivelmente a maneira como o sujeito pensa a si próprio, a maneira como interpreta as próprias emoções, o modo de se conduzir na relação com os outros", indicando como seria impossível pensar em uma expansão da nomeação advinda dos transtornos psiquiátricos como neutra, sem efeitos. 


\section{Conclusão}

O DSM foi, ao longo dos anos, aumentando as suas categorias de transtornos e, cada vez mais, parece ter se tornado um objeto imprescindível nas formas de classificação do sofrimento. Esse referencial sustenta, contemporaneamente, uma disciplina do diagnóstico a-teórica, divorciada da psicopatologia, o que contribui para o esmorecimento de um debate etiológico acerca do sofrimento psíquico. Tais mudanças sugerem uma maior agilidade diagnóstica, conjuntamente a uma proliferação dos transtornos, já que a intensificação da comorbidade é um de seus efeitos. O DSM-V, por sua vez, parece concretizar a praticidade, a funcionalidade e a flexibilidade na feitura dos diagnósticos, o que acelera e dissemina os usos e nomeações ligadas à saúde mental. Retomando a etimologia da palavra diagnóstico se pode dizer que a praticidade e funcionalidade do manual favoreceriam mais sua vertente de conclusão do que de processo, como se o diagnóstico fosse elemento final em direção à cura. Neste caso, o diagnóstico se faria de forma mais rápida e fácil, o que poderia estar contribuindo para sua expansão.

$\mathrm{Na}$ atualidade, um dos campos que reflete a expansão diagnóstica é o educativo. Fato é que a proliferação dos transtornos parece ter chegado com força no terreno da escola. Uma classificação médica, baseada principalmente no conjunto de sintomas observáveis, parece ter ganhado seu matiz educativo ao emprestar nomes aos comportamentos de alunos e alunas, que não correspondem ao esperado. Educadores passam a ser, então, co-partícipes do diagnóstico em saúde mental. Aponta-se, por exemplo, como uma escala avaliativa propõe o pré-diagnóstico pelo professor. A questão de centralizar o diagnóstico em comportamentos observáveis reduz a participação do sujeito na narrativa de seu sofrimento, muitas vezes, calando a própria criança e adolescente. Também pode estar contribuindo para uma observação avaliativa do educador que esmorece, senão aniquila, a sua própria implicação na cena educativa. Como já referida, a questão do laudo médico para a utilização da sala de recursos nas escolas aponta para um deslocamento do diagnóstico da situação de ensino e aprendizagem, papel de educadores, para uma patologização da aprendizagem articulada a um transtorno, geralmente, previsto pelo DSM.

\section{Referências}

APA - American Psychiatric Association. Diagnostic and statistical manual of mental disorders. Arlington: American Psychiatric Association, 2013.

AMERICAN PSYCHIATRIC ASSOCIATION. Diagnostic and Statistical Manual of Mental Disorders. Arlington: American Psychiatric Association, 1980.

AURÉLIO. Dicionário online de português. Disponível em: https:/www.dicionarioaurelio.com.br/diagnostico/. Acesso em: 31 jan. 2019.

BOARINI, M.L.; BORGES, R.F. Demanda infantil por serviços de saúde mental: sinal de crise. Estud. Psicol., v.3, n.1, p.83108, $1998 \quad$ doi: http://dx.doi.org/10.1590/S1413294X1998000100005.

BEZERRA JUNIOR, B. A psiquiatria contemporânea e seus desafios In: ZORZANELLI, R. et al. (Org.). A produção de diagnósticos em Psiquiatria Contemporânea. Rio de Janeiro: Garamond, 2014. p.9-30.

BIRMAN, J. Drogas, performance e psiquiatrização na contemporaneidade. Ágora, v.17, p.23-37, 2014. doi: http:// dx.doi.org/10.1590/S1516-14982014000300003.

CALAZANS, R. et al. Manifesto de São João del-Rei- Brasil - em prol de uma psicopatologia clínica, In: CALAZANS, R.; KYRILLOS NETO F. (Org.). Psicopatologia em debate: controvérsias sobre os DSMs. Barbacena: Universidade do Estado de Minas Gerais, 2012. p.183-200.

CALIMAN, L.V. A constituição sócio-médica do "fato TDAH". Psicol. Soc., v.21, n.1, p. 135-144, 2009. doi: http:// dx.doi.org/10.1590/S0102-71822009000100016.

CANGUILHEM, G. Qu'est-ce que la Psychologie? Cahiers pour l'Analyse, v.1, n.2, p.77-86, 2014.

CARNEIRO, C.; COUTINHO, L.G. Infância e adolescência: como chegam as queixas escolares à saúde mental?. Educ. Rev., n.56, p.181-192, 2015. doi: http://dx.doi.org/10.1590/01044060.37764.

COLLARES, C.A.L. Controle e medicalização da infância. Desidades, v.1, p.1-5, 2013.

COSTA, J.C. Augusto Comte e as origens do Positivismo. Rev. História, n.3, 1950.

COUTINHO, L.G.; CARNEIRO, C. Infância, adolescência e mal-estar na escolarização: interlocuções entre a psicanálise e a educação. Psicol. Clin., v.28, n.2, p.109-129, 2016.

DUNKER, C.I.L. A neurose como encruzilhada narrativa: psicopatologia psicanalítica e diagnóstica psiquiátrica. In: ZORZANELLI, R.; BEZERRA JUNIOR, B.; COSTA, J.F. (Org.). A produção de diagnósticos em Psiquiatria Contemporânea. Rio de Janeiro: Garamond, 2014. p.69-106.

FÓRUM SOBRE MEDICALIZAÇÃO DA EDUCAÇÃO E DA SOCIEDDE, 2019. Disponível em: http://medicalizacao.org.br/. Acesso em: 12 set. 2019.

FOUCAULT, M. Doença mental e psicologia. Rio de Janeiro: Tempo Brasileiro, 1968.

FOUCAULT. História da loucura na Idade Clássica. São Paulo: Perspectiva, 1972.

FOUCAULT. Le pouvoir Psiquiatrique. Cours au Collège de France, 1973-1974. Paris: Gallimard, 2003.

FOUCAULT . Vigiar e punir: história da violência nas prisões. Petrópolis: Vozes, 1981.

ILLICH, I. A expropriação da saúde: nêmesis da medicina. Rio de Janeiro: Forense, 1982.

JERUSALINSKY, J.; LUGON, R. Inclusão sem laudo é um direito da criança. Estadão, 2016. Acesso em 09 ago. 2019.

LIMA, R. Classificação e psicopatologia da infância e adolescência: a contribuição francesa chega ao Brasil. Estilos da Clínica, v.24, n.1, p.173-177, 2019.

MARCON, G.T.G.; SARDAGNA, H.V.; SCHUSSLER, D. O questionário SNAP-IV como auxiliar psicopedagógico no diagnóstico PRELIMINAR do Transtorno de déficit de atenção e hiperatividade (TDAH). Constr. Psicopedag., v.24, n.25, p.99$118,2016$. 
MOYSÉS, M.A.A. A institucionalização invisivel: crianças que não-aprendem-na-escola. Campinas: Mercado de Letras, 2001.

PATTO, M.H.S. A produção do fracasso escolar. Histórias de submissão e rebeldia. São Paulo: Casa do Psicólogo, 2000.

RESENDE, M.S.; CALAZANS, R. Neurose e psicose na CID10 e DSM-IV: o que é ignorado?. Analytica, v.2, n.3, p.145174, 2013 .
SIMÕES, R.S. et al. Etimologia de termos morfológicos. 2014. Disponível em: https://pt.slideshare.net/kishin3/etimologia-determos-morfolgicos

VIEGAS, L.S.; HARAYAMA, R.M.; SOUZA, M.P.R. Apontamentos críticos sobre estigma e medicalização à luz da psicologia e da antropologia. Ciênc. Saúde Coletiva, v.20, n.9, p.2683-2692, 2015 . doi: http://dx.doi. org/10.1590/1413-81232015209.08732015 